\title{
MSMES BECOME THE EARLY FOUNDATION OF INDONESIA'S ECONOMIC RECOVERY
}

\section{(ANGELIA/ 130219057/ KP B)}

The year 2020 is quite a difficult year for people around the world, especially Indonesia. Covid 19 has had a wide impact. Almost everything that happens in the activities and mobility of the community must be stopped temporarily. Indonesia feels the impact of Covid is quite large, especially in the health sector and also the economy. The expenditure that Indonesia has spent to overcome the impact of Covid is quite large, but for state income it is almost inversely proportional. According to the Central Statistics Agency (BPS), Indonesia recorded a decline in economic growth of minus five point thirty-two percent $(-5.32 \%)$ in the second quarter. There are so many businesses or businesses that are closed so that there are many layoffs of employees. People's purchasing power decreases because people focus on the necessities of life in order to survive in times of uncertainty as long as possible. ensuring that things get back to normal is a big challenge for the country. Because in addition to the hampered domestic economy, abroad too. Access for Indonesia to carry out Export-Import is hampered because sea and air transportation are very difficult. Each country is trying to survive with themselves because they are equally overwhelmed.

The impact of Covid 19 in Indonesia is increasingly felt for the lower middle class. To survive to meet daily needs is quite difficult. Most people who have a lower-middle economy have jobs that require them to leave their homes and engage in direct activities. This kind of work was certainly disrupted and even stopped during the Covid 19 pandemic. The income of the middle to lower class is not too large and sometimes it is only just right for eating and making a living, so they don't have financial reserves (savings) so that in times of pandemic uncertainty they don't have preparation at all. This makes the government have to intervene directly to help the existing community. At the beginning of Covid 19, the first assistance provided by the government was free medical assistance for Covid 19, then social assistance, even quota assistance for schools and many more subsidies and new regulations that eased special people during the pandemic. 
Micro, Small and Medium Enterprises (MSMEs) at the beginning of the pandemic experienced a drastic decline. People are still too shocked by the situation that requires all activities to be limited. But slowly but surely with more free time due to government programs, namely study from home and work from home, making people look for ideas to make a living and be productive. In the third quarter, the Indonesian economy improved slightly, although its economic growth was still minus, but was better than the previous quarter. This turned out to be due to one of them, namely the emergence of several new MSMEs that began to move people's purchasing power.

Seeing the spark of a new community spirit in doing business, there are many responses from experts who encourage the government to be able to facilitate. Empowerment and comprehensive support for small businesses must be one of the government's priorities when transforming by reorganizing the national economy in an effort to encourage economic growth, prevent recession and the Covid-19 pandemic crisis, and significantly reduce unemployment and poverty. The number of micro and informal businesses is so massive that the empowerment of ultra micro businesses such as hawkers and street vendors seems to be able to significantly boost the national economy (Tayibnapis 2021). The expert's statement seemed to invite the government not only limited to micro-business but really all people, especially people who are really experiencing economic difficulties. Because basically it is those who are under it who need immediate help. However, it is not only physical assistance in the form of money and basic materials, but also long-term assistance, namely knowledge and skills. Business opportunities may not have been found due to limited knowledge and information. 
MSMEs that grow during these difficult times attract a lot of parties. Many parties are enthusiastic and believe that MSMEs are one of the most potential pillars of the country's economic recovery. The progress of MSMEs is apparently supported by existing technological advances. Technology and information systems that continue to develop make everything easier and more practical. Most of these MSMEs that appear are MSMEs who start businesses from home, such as selling food and doing business using online applications, which are currently widely available in Indonesia. Seeing this, several Indonesian start-up and e-commerce companies provided socialization on how to sell online, were given training, taught about online payments and others. The attention of several large companies is useful because it is very relevant and can actually be applied, especially in situations where people are still not free to travel outside their homes. In addition, the lifestyle of today's people who tend to want to be fast and practical makes online business opportunities bigger. This online business opportunity can be done by anyone because almost everyone has a smartphone and has enjoyed the sophistication of the internet.

The desire to promote Micro, Small and Medium Enterprises (MSMEs) does not only arise from entrepreneurs, but the government has also begun to move. Many regional governments are starting to become aware of, monitor, follow and even contribute directly to providing support for MSMEs. Some regions have also begun to mobilize their communities to start businesses and are willing to provide assistance to prospective business actors or MSMEs who are really serious. The assistance provided varies from providing capital, providing training, providing facilities and infrastructure, and so on. In addition to local governments, the central government is also moving to help the country's economy, one of which is by changing several business regulations. The government hopes that by easing the existing regulations, business people have more opportunities to do or expand their business.

MSMEs need to be continuously improved so that they can be integrated into national production systems or global supply chains. MSMEs must be able to work on local advantages to produce special products so that they can be more competitive in both the domestic and international markets (Tayibnapis 2021). MSME products should not be of high quality but only produced and packaged properly. Because the target or achievement in business is not only where the product is sold but how the product has a long life cycle and continues to survive along with the times. 


\section{RESOURCES}

Tayibnapis, A. Z., Wuryaningsih, L. E., \& Gora, R. (2021). Medium, Small and Medium

Enterprises and Digital Platforms. South Asian Journal of Social Studies and Economics, 10(2), 1019. 